\section{Military Technical College Kobry El-Kobbah, Cairo, Egypt}

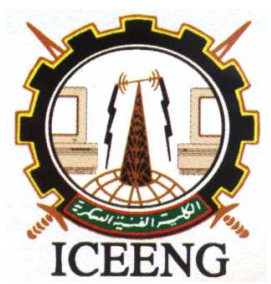

\title{
Maximum MMF reduction using the Newton Raphson method
}

$$
\text { By }
$$

\author{
Derya Ahmet Kocabaş*
}

\section{$\underline{\text { Abstract: }}$}

This paper accompanies and complements a related companion paper [1]. Previous contributions have discussed the disturbing effects of space harmonics in induction motors, and several techniques to reduce or eliminate them have been proposed. Since these unwanted effects are produced by the stator winding, it is possible to eliminate or at least to significantly reduce some of the space harmonics, by changing the winding structure that is responsible for producing them. It is shown here that, by regarding the mmf waveform as a stepped function, this can be achieved by optimizing the slot positions and the number of conductors in the slots, using software designed for Matlab, and prepared using the Newton Raphson method. The conventional waveform is analyzed and optimized for convenient numbers of slots, and the necessary mathematical relationships are presented, together with equations for the chosen waveform, and a flow-chart for the associated software.

\section{Keywords:}

Electrical machinery design, space harmonics, machine windings, Newton Raphson method

* Electrical \& Electronics Eng. Fac., Istanbul Technical University, Istanbul, Turkey Electronic \& Electrical Eng. Dep. Loughborough University, Loughborough, UK 


\section{Introduction:}

Many authors have shown that space harmonics have negative effects on the performance of induction motors [2-5] and they therefore have a relationship with the winding and core design. To overcome many of these effects, techniques have been developed usually consisting of new winding arrangements accommodated in the same stator core. However, by using a different method originated by the present author [6], [7], it is possible to eliminate almost entirely the most prominent space harmonics and their undesirable effects [8], [9].

The new method requires optimization of both the slot positions and the number of conductors in the slots. After completing this process, the mmf waveform is cleaned of all the main space harmonics, other than multiples of 3. It is shown that this approach is possible for motors having a number of slots which is a multiple of 12 , and as the number of slots per pole pair increases, so to does the number of eliminated harmonics.

In this paper, only the mathematical basis, equations and relationships are given since the effects of this technique were analyzed in earlier publications [6-9]. To explain briefly the advantages and disadvantages of the new technique a design programme was written and its reliability established by re-designing a motor obtained from a manufacturer [6], [7]. To obtain the optimized structure, the new calculation methods, slot optimization and tooth calculation published in the companion paper are adapted for the novel design. The novel stator core with the new winding structure is designed while the basic concepts are kept unchanged [6], [8]. The results obtained are summarized in the present paper [6-9].

\section{MMF Waveform to be Optimized:}

The mmf in the airgap of an induction motor is equal to the product of the current and the conductor distribution along the air gap. Since the conductor distribution is not sinusoidal and the iron core is not continuous, the mmf waveform is a stepped periodic function that is the repeated every pole pair. If the $\mathrm{mmf}$ is analyzed under one pole pair it can be expressed in terms of a Fourier Series. In order to calculate the Fourier coefficients, the general principles of an mmf waveform need to be observed.

In a conventional induction motor with a 3-phase winding, there are six phase spreads per pole pair, each with an electrical angle of $60^{\circ}$. Assuming an arbitrary phase current of $1 \mathrm{~A}$, the mmf for one phase increases in one spread of one phase and decreases in the other, with inbetween a flat top and bottom each of $120^{\circ}$, as shown in Figure 1. 


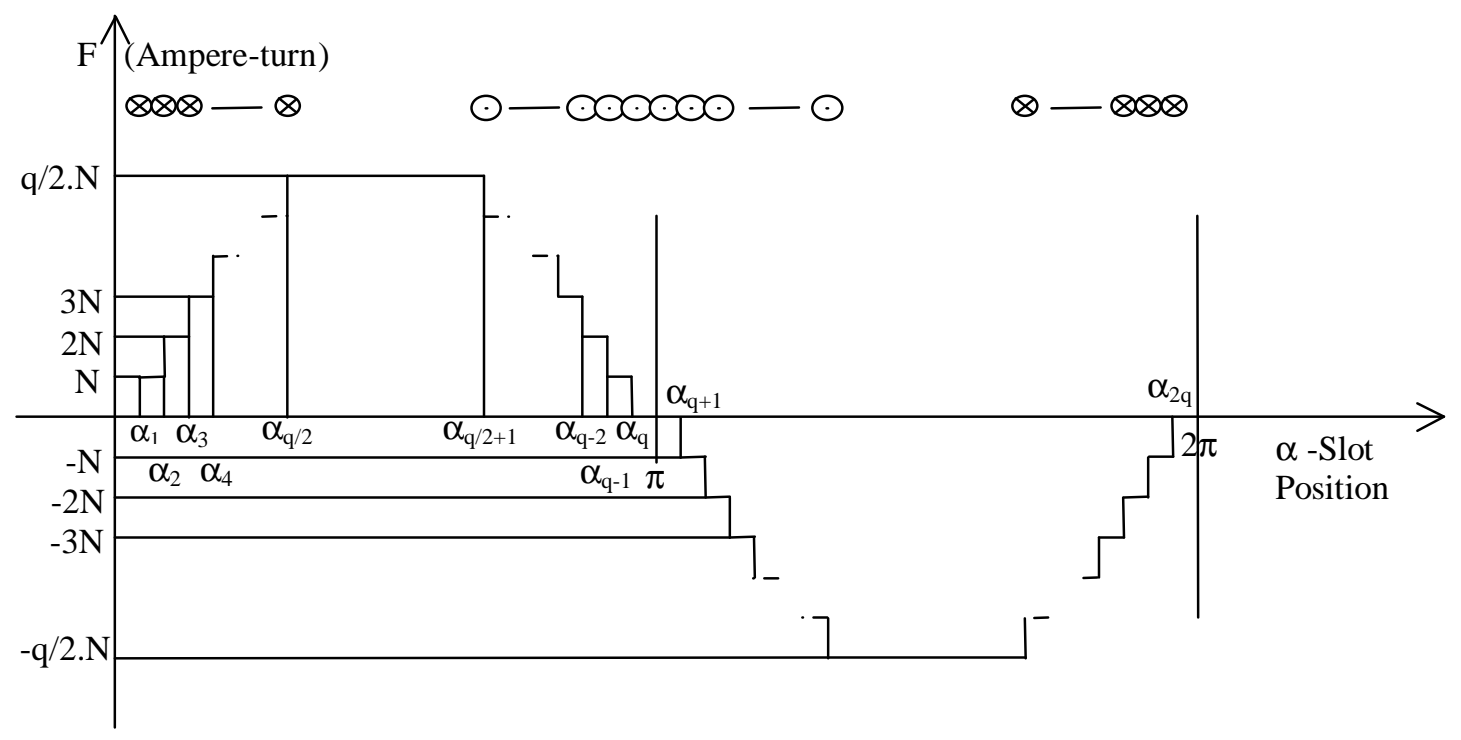

Figure 1: $M M F$ distribution of conventional winding ( $N=$ conductors per slot, current=1 A)

\section{Fourier Series:}

A periodic function can be expressed in terms of a Fourier series [10] as in Equation 1 and the coefficients calculated using Equations 2, 3 and 4, where $\mathrm{a}_{0}$ is the mean value of the function which here is equal to zero.

$$
\begin{aligned}
& f(x)=a_{o}+\sum_{n=1}^{\infty}\left[a_{n} \cdot \cos (n \omega t)+b_{n} \cdot \sin (n \omega t)\right] \\
& a_{0}=\frac{1}{T} \int_{0}^{T} f(x) \cdot d x \\
& a_{n}=\frac{2}{T} \int_{0}^{T} f(x) \cdot \cos (n \omega t) \cdot d x \\
& b_{n}=\frac{2}{T} \int_{0}^{T} f(x) \cdot \sin (n \omega t) \cdot d x
\end{aligned}
$$

When there is half-wave symmetry one of the coefficient families is always zero and only one type of harmonic remains, depending on whether the function is even or odd. If the waveform has quarter-wave symmetry even harmonics are always absent, and only odd harmonics are present [10]. 


\section{Fourier Analysis:}

A programme was developed to analyze and optimize the waveform of Figure 1, with calculation of the harmonics being possible for any desired number of harmonics. In order to check the reliability of the programme, all harmonic coefficients are calculated, although most of these are known in advance to be zero. Since $\mathrm{a}_{0}=0$, the harmonic expressions for Figure 1 are calculated using Equations 5 and 6 , where $\mathrm{F}$ is the $\mathrm{mmf}$ value at the slot centre, $\alpha$ is the slot position and $n$ is the harmonic order.

$a_{n}=\frac{2}{2 \pi}\left[\int_{\alpha_{1}}^{\alpha_{2}} F_{1} \cdot \cos n \alpha \cdot d \alpha+\ldots+\int_{\alpha_{i}}^{\alpha_{i+1}} F_{i} \cdot \cos n \alpha \cdot d \alpha+\ldots+\int_{\alpha_{2 q-1}}^{\alpha_{2 q}} F_{2 q} \cdot \cos n \alpha \cdot d \alpha\right]$
$b_{n}=\frac{2}{2 \pi}\left[\int_{\alpha_{1}}^{\alpha_{2}} F_{1} \cdot \sin n \alpha \cdot d \alpha+\ldots+\int_{\alpha_{i}}^{\alpha_{i+1}} F_{i} \cdot \sin n \alpha \cdot d \alpha+\ldots+\int_{\alpha_{2 q}-1}^{\alpha_{2 q}} F_{2 q} \cdot \sin n \alpha \cdot d \alpha\right]$

The coefficients are determined from Equations 7 and 8 where $a_{n}$ is zero, because the mmf waveform has half-wave symmetry and $b_{n}$ has only odd order harmonic terms, because of the quarter-wave symmetry.

$$
\begin{aligned}
& \mathrm{a}_{\mathrm{n}}=\frac{1}{\mathrm{n} \pi} \sum_{\mathrm{i}=1}^{2 \mathrm{q}-1} \mathrm{~F}_{\mathrm{i}}\left[\sin \left(\mathrm{n} \cdot \alpha_{\mathrm{i}+1}\right)-\sin \left(\mathrm{n} \cdot \alpha_{\mathrm{i}}\right)\right] \\
& \mathrm{b}_{\mathrm{n}}=\frac{1}{\mathrm{n} \pi} \sum_{\mathrm{i}=1}^{2 \mathrm{q}-1} \mathrm{~F}_{\mathrm{i}}\left[\cos \left(\mathrm{n} \cdot \alpha_{\mathrm{i}}\right)-\cos \left(\mathrm{n} \cdot \alpha_{\mathrm{i}+1}\right)\right]
\end{aligned}
$$

\section{Newton Raphson Method:}

The Newton Raphson method used for optimization depends on calculating a displacement around a proposed solution in " $\mathrm{k}$ " dimensional space in order to shift the first solution point [11]. After obtaining the displacement, a new calculation is performed around the displaced solution point. This progress continues until the displacement reaches a desired value. If the variable matrix is $[\mathrm{x}]$, the function matrix to be calculated is $[\mathrm{f}(\mathrm{x})]$, the displacement matrix is $\mathrm{dx}$ and the partial differential matrix is $\mathrm{d}[\mathrm{f}(\mathrm{x})] / \mathrm{dx}$, then

$[\mathrm{x}]=\left[\begin{array}{llllll}\mathrm{x}_{1} & \mathrm{x}_{2} & \ldots & \mathrm{x}_{\mathrm{i}} & \ldots & \mathrm{x}_{\mathrm{k}}\end{array}\right](\mathrm{i}=1,2, \ldots \mathrm{k})$ 
$[f(x)]=\left[\begin{array}{c}f_{1}(x) \\ f_{2}(x) \\ M \\ f_{i}(x) \\ M \\ f_{r}(x)\end{array}\right] \quad(i=1,2, \ldots . r)$

$\frac{d[f(x)]}{d x}=\left[\begin{array}{ccccc}\frac{d\left[f_{1}(x)\right]}{d x_{1}} & L & \frac{d\left[f_{1}(x)\right]}{d x_{j}} & L & \frac{d\left[f_{1}(x)\right]}{d x_{k}} \\ \frac{d\left[f_{i}(x)\right]}{d x_{1}} & O & \frac{d\left[f_{i}(x)\right]}{d x_{j}} & L & \frac{d\left[f_{i}(x)\right]}{d x_{k}} \\ M & O & M & O & M \\ \frac{d\left[f_{r}(x)\right]}{d x_{1}} & L & \frac{d\left[f_{r}(x)\right]}{d x_{j}} & L & \frac{d\left[f_{r}(x)\right]}{d x_{k}}\end{array}\right]$

$$
\left(\begin{array}{l}
\mathrm{i}=1,2, \ldots \mathrm{r} \\
\mathrm{j}=1,2, \ldots \mathrm{k}
\end{array}\right)
$$

The value of the displacement matrix is calculated around a given solution point $\left[\mathrm{x}_{0}\right]$ using Equation 12.

$$
\left.[\mathrm{dx}]\right|_{\left[\mathrm{x}=\mathrm{x}_{0}\right]}=(-1) \cdot\left[\frac{\mathrm{d}\left[\mathrm{f}\left(\mathrm{x}_{0}\right)\right]}{\mathrm{dx}}\right]^{-1} \cdot\left[\mathrm{f}\left(\mathrm{x}_{0}\right)\right]
$$

The second value for $[\mathrm{x}]$ is $\left[\mathrm{x}_{0-2}\right]$ and it is calculated as in Equation 13 using the previous solution matrix $\left[\mathrm{x}_{0-1}\right]$.

$\left[\mathrm{x}_{0-2}\right]=\left[\mathrm{x}_{0-1}\right]+\left.[\mathrm{dx}]\right|_{\left[\mathrm{x}=\mathrm{x}_{0}\right]}$

This calculation ceases when $d x$ is equal to the intended value.

\section{Optimization of MMF:}

The $[\mathrm{x}]$ matrix consists of the slot positions $[\alpha]$ and ampere-turn values $[\mathrm{F}]$ to be optimized. Because of the quarter-wave symmetry, $\mathrm{q} / 2$ slot positions and $\mathrm{q} / 2 \mathrm{mmf}$ 
values in the quarter-wave need to be considered, where $\mathrm{q}$ is the number of slots per pole per phase. In the optimization process, the total number of turns per phase is kept constant at 200 to obtain a magnitude of 100 A-turns and this enables the solutions to easily be adapted to a different number of turns. This process decreases the number of variables by 1 and (q-1) harmonics therefore remain to be optimized. The value of 100 is not used in optimization but only in the harmonic calculation [6].

$$
\begin{aligned}
& {[\alpha]=\left[\begin{array}{llll}
\alpha_{1} & \alpha_{2} & \ldots & \alpha_{\mathrm{q} / 2}
\end{array}\right]} \\
& {[\mathrm{F}]=\left[\begin{array}{lllll}
\mathrm{F}_{1} & \mathrm{~F}_{2} & \ldots & \mathrm{F}_{\mathrm{q} / 2-1} & 100
\end{array}\right]} \\
& {[\mathrm{x}]=[[\alpha] \quad[\mathrm{F}]]}
\end{aligned}
$$

Since the number of harmonics to be optimized is (q-1), it is better to use this for the most prominent harmonics. Only harmonics of order $(6 \mathrm{k} \pm 1)$, beginning from the lowest order harmonics, were optimized, since it is known that harmonics of order 3 do not exist in a 3-phase mmf. [f(x)] consists of $(6 \mathrm{k} \pm 1)$ order harmonics to be optimized with a number of rows of $(\mathrm{q}-1)$. For maximum mmf harmonic reduction, the values in $[\mathrm{f}(\mathrm{x})]$ are desired to be zero at the end of the optimization. The targeted harmonics in $[\mathrm{f}(\mathrm{x})]$ are given in Equations 17 and 18,

$$
[f(x)]=\left[\begin{array}{c}
f_{1}(x) \\
f_{2}(x) \\
M \\
f_{i}(x) \\
M \\
f_{r}(x)
\end{array}\right]=\left[\begin{array}{c}
b_{5} \\
b_{7} \\
M \\
b_{n} \\
M \\
b_{3 q-1}(x)
\end{array}\right] \quad(i=1,2, \ldots,(3 q-1))
$$

with the targeted harmonics being

$b_{n}=\frac{4}{n} \cdot \pi \sum_{i=1}^{\pi / 2} F_{i}\left[\cos \left(n \cdot \alpha_{i}\right)-\cos \left(n \cdot \alpha_{i+1}\right)\right]$

The partial differential matrix is calculated using Equations 20 and 21. 


$$
\begin{aligned}
& \frac{d[f(x)]}{d x}=\left[\frac{\partial b_{n}}{\partial \alpha_{i}} \frac{\partial b_{n}}{\partial F_{j}}\right] \quad\left(\begin{array}{c}
i=1,2, \ldots(q / 2) \\
j=1,2, \ldots(q / 2-1)
\end{array}\right) \\
& \frac{\mathrm{d}[\mathrm{f}(\mathrm{x})]}{\mathrm{dx}}=\left[\begin{array}{cccccccc}
\frac{\partial \mathrm{b}_{5}}{\partial \alpha_{1}} & \frac{\partial \mathrm{b}_{5}}{\partial \alpha_{2}} & \mathrm{~L} & \frac{\partial \mathrm{b}_{5}}{\partial \alpha_{\mathrm{q} / 2}} & \frac{\partial \mathrm{b}_{5}}{\partial \mathrm{F}_{1}} & \frac{\partial \mathrm{b}_{5}}{\partial \mathrm{F}_{2}} & \mathrm{~L} & \frac{\partial \mathrm{b}_{5}}{\partial \mathrm{F}_{\mathrm{q} / 2-1}} \\
\frac{\partial \mathrm{b}_{7}}{\partial \alpha_{1}} & \frac{\partial \mathrm{b}_{7}}{\partial \alpha_{2}} & \mathrm{~L} & \frac{\partial \mathrm{b}_{7}}{\partial \alpha_{\mathrm{q} / 2}} & \frac{\partial \mathrm{b}_{7}}{\partial \mathrm{F}_{1}} & \frac{\partial \mathrm{b}_{7}}{\partial \mathrm{F}_{2}} & \mathrm{~L} & \frac{\partial \mathrm{b}_{7}}{\partial \mathrm{F}_{\mathrm{q} / 2-1}} \\
\mathrm{M} & \mathrm{M} & \mathrm{O} & \mathrm{M} & \mathrm{M} & \mathrm{M} & \mathrm{O} & \mathrm{M} \\
\frac{\partial \mathrm{b}_{3 \mathrm{q}-1}}{\partial \alpha_{1}} & \frac{\partial \mathrm{b}_{3 \mathrm{q}-1}}{\partial \alpha_{2}} & \mathrm{~L} & \frac{\partial \mathrm{b}_{3 \mathrm{q}-1}}{\partial \alpha_{\mathrm{q} / 2}} & \frac{\partial \mathrm{b}_{3 \mathrm{q}-1}}{\partial \mathrm{F}_{1}} & \frac{\partial \mathrm{b}_{3 \mathrm{q}-1}}{\partial \mathrm{F}_{2}} & L & \frac{\partial \mathrm{b}_{3 \mathrm{q}-1}}{\partial \mathrm{F}_{\mathrm{q} / 2-1}}
\end{array}\right]
\end{aligned}
$$

The elements of $d[f(x)] / d x$ are;

$$
\begin{array}{ll}
\frac{\partial b_{n}}{\partial \alpha_{1}}=\frac{-4}{\pi} \cdot F_{1} \cdot \sin \left(n \cdot \alpha_{1}\right) & \\
\frac{\partial b_{n}}{\partial \alpha_{i}}=\frac{-4}{\pi} \cdot\left(F_{i-1}-F_{i}\right) \cdot \sin \left(n \cdot \alpha_{i}\right) & (i=2,3, \ldots, q / 2) \\
\frac{\partial b_{n}}{\partial F_{i}}=\frac{4}{n \cdot \pi} \cdot\left[\cos \left(n \cdot \alpha_{i}\right)-\cos \left(n \cdot \alpha_{i+1}\right)\right] & (i=1,2, \ldots,(q / 2-1))
\end{array}
$$

The dimensions of the matrices are $[1 \mathbf{X}(\mathrm{q}-1)]$ for $[\mathrm{x}],[(\mathrm{q}-1) \mathbf{X} 1]$ for $[\mathrm{f}(\mathrm{x})]$ and $[(q-1) X(q-1)]$ for $d[f(x)] / d x$. This means $d[f(x)] / d x$ is square with a dimension of $q$, and has an inverse matrix [6].

\section{Optimization Software:}

Using this method enables (q-1) harmonics to be exactly eliminated. But this requires calculating a slot position with high accuracy, without causing a great change in the harmonic spectrum. Instead of calculating the slot positions with great accuracy, it is preferable to make the variables almost zero by rounding up and down the slot positions. The resulting change in the harmonic spectrum is extremely small.

The optimized mmf waveform must satisfy certain conditions and these must be checked during every cycle of the optimization calculations. The waveform must keep the main characteristics of the method and the programme must be halted, if the first 


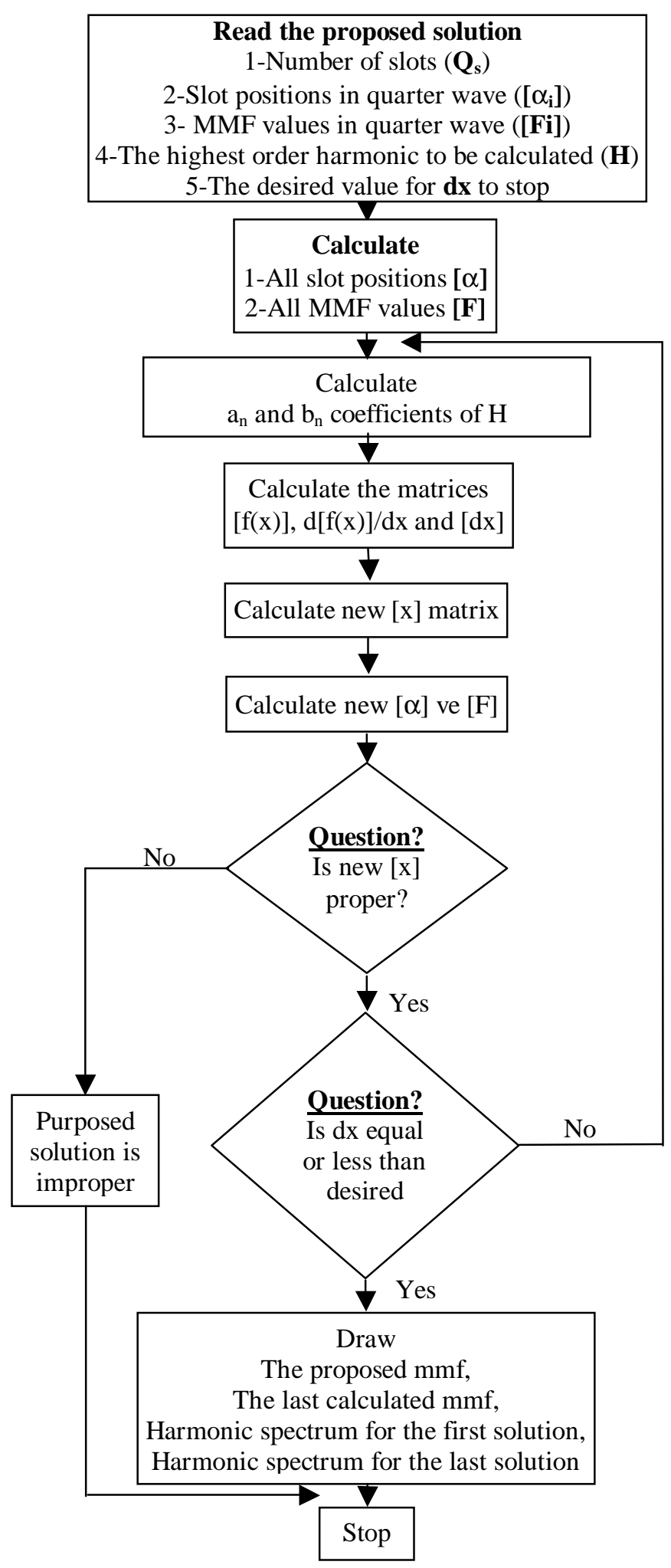

Figure (2): Flow-chart of the optimization software 
slot position is less than zero, the $(i+1)^{\text {th }}$ slot position is less than the $i^{\text {th }}$ position, or the $(\mathrm{q} / 2)$ th slot position is greater than $\pi / 2$ in any step of the calculation. The flow chart of the optimization software is shown in Figure 2.

This flow-chart was realized in Matlab. The programme needs the numbers of slots, the slot positions and the ampere-turn values in the quarter-wave mmf distribution, the highest order harmonic to be calculated and the minimum displacement value to halt the programme. The results are printed to screen with a comparison of waveform and harmonic spectrum for the given point and the optimized solution in the last cycle.

The results are all checked for a high winding factor by two different programmes depending on two different calculation methods [12-17].

\section{Sample Solution:}

Results to eliminate the space harmonics are calculated for values of $q / 2=2,3,4,5$ \& 6 and the winding factor is obtained for each solution. Since the results of the optimization are published elsewhere [6], [7] only the results of optimization for $q / 2=3$ is given here. The harmonic spectrum and optimized waveform for this number of slots are shown in Figures 3 and 4, respectively.

The results prove the absence of the most prominent harmonics that have disturbing effects on the performance of a standard machine. There is however a slight decrease in the fundamental and a small increase in the first existing harmonics, although this has negligible effect on the machine performance, and the increase in these harmonics and the $3^{\text {rd }}$ order harmonics are unimportant.

\section{Conclusions:}

To reduce the disturbing effects of space harmonics, an analysis of the mmf waveform for a conventional winding was performed and the harmonics were calculated using a Fourier representation. The Newton-Raphson method was used for numerical optimization and this method was realized in Matlab. The optimization calculations and the flow chart are given with results obtained for $\mathrm{q} / 2=2,3,4,5 \& 6$ slots per pole.

It is proved that (q-1) space harmonics can be eliminated or almost eliminated by using this method, while preserving a high fundamental winding factor between 0.922 and 0.911 for the solutions examined. The effects of the planned changes were analyzed elsewhere when the numerical results of the optimization was implemented in a particular design [6], [8], [9]. The new design with the different slot displacements and 


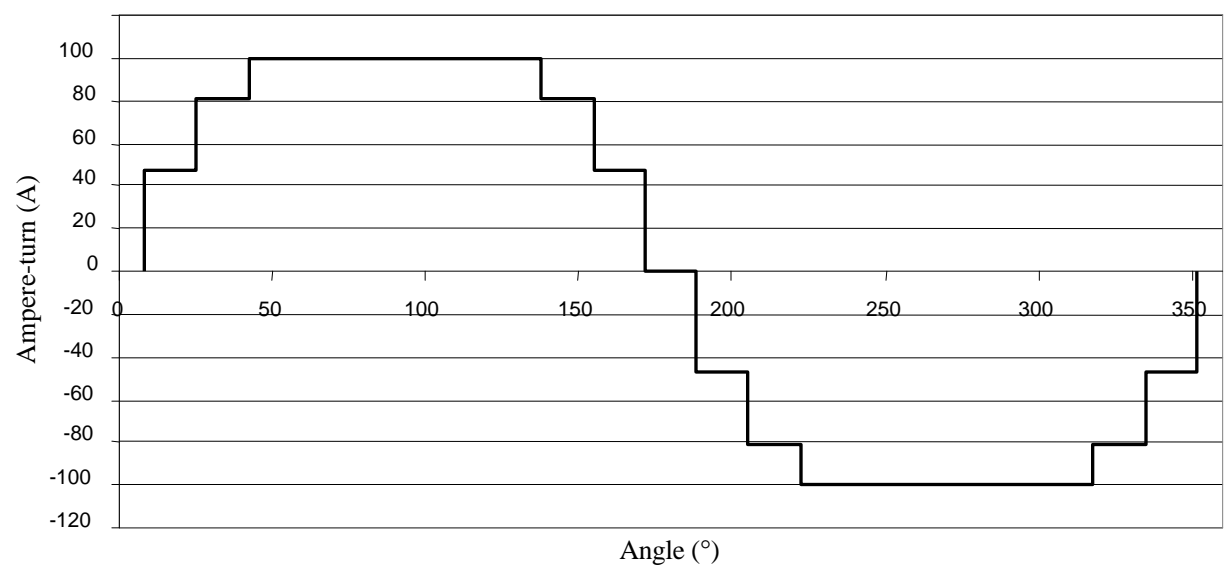

Figure (3): Optimized $M M F$ for $q / 2=3$

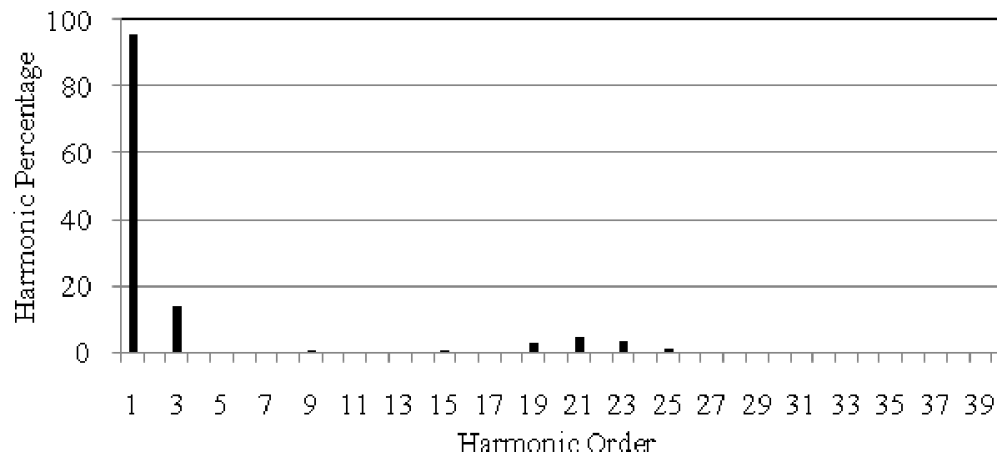

Figure (4): Optimized harmonic spectrum for $q / 2=3$

number of conductors per slot was performed using a design programme [6] and the results were shown to be successful by using a magnetic analysis programme [6], [7]. Calculated torque and speed curves for both motors including the space harmonics effects [6], [9] show that this method improves to the performance of the motor giving increased efficiency, less copper usage, but has the disadvantages of increased iron loss and iron weight [6], [8].

\section{Acknowledgement:}

Derya Ahmet Kocabaş thanks to Prof. Dr. Ahmet Faik Mergen of Electrical and Electronics Faculty at Istanbul Technical University and Prof. Ivor Smith of the Electronic and Electrical Engineering Department at Loughborough University for their valuable contributions. 


\section{References:}

[1] Kocabaş, D.A., "Innovative Design for Maximum MMF Reduction," Proc. ICEENG 2008, Cairo, May, 2008

[2] Mergen,A.F., "Asenkron Motorlarda Besleme Gerilimi Frekansinin Değiştirilmesi ile Devir Sayısı Ayar Yöntemlerinin Kritik Etüdü,”(Critical Research of Speed Control Methods by Changing the Frequency of the Terminal Voltage in Induction Machines) Assistant Professorship Thesis, Turkish, ITU Electrical \& Electronics Faculty, Istanbul, 1982

[3] Smith, I.R. and Layton J.M., "Harmonic Elimination in Polyphase Machines by Graded Windings," Proc. IEE, Vol. 110, No.9, pp 1640-1648, 1963

[4] Chalmers, B.J., "AC Machine Windings with Reduced Harmonic Content," Proc. IEE, Vol. 111, No.11, pp 1859-1863, 1964

[5] Hughes, A., "New 3-Phase Winding of Low MMF-Harmonic Content," Proc. IEE, Vol. 117, No.8, pp 1657-1666, 1970

[6] Kocabaş, D.A., "Asenkron Makinalarda Uzay Harmoniklerinin Etkilerini Azaltmaya Katkllar,"(Contributions to Reduce the Effects of Space Harmonics in Induction Machines) PhD Thesis, Turkish, ITU Science \&Technology Institute, Istanbul, 2004

[7] Kocabaş, D.A. and Mergen, A.F., "A Novel Method to Reduce the Effects of Space Harmonics in Alternating Current Machines," Proc. ISIE 2008, Cambridge, July, 2008, unpublished

[8] Kocabaş, D.A. and Mergen, A.F., "Performance and Magnetic Analysis of the Novel Stator Structure Compared With a Standard Induction Machine," Proc. ISIE 2008, Cambridge, July, 2008, unpublished

[9] Kocabaş, D.A. and Mergen, A.F., "Comparison of the Torque \& Slip Curves for a Standard Squirrel Cage Induction Motor with those of a Motor with a Novel Winding Arrangement," Proc. ISIE 2008, Cambridge, July, 2008, unpublished

[10] Dyke, P., “An Introduction to Laplace Transforms and Fourier Series," Springer, London, 2000

[11] Demirel A., "Bir Soğutucuyи Güneş Enerjisi ile Besleyen Sistemin Tasarımı," (Design of System Which Feeds A Cooler with Solar Power), MSc Thesis, Turkish, ITU Science \&Technology Institute, Istanbul, 1990

[12] Kocabaş, D.A., "Alternatif Akım Makinalarında Uzay Harmoniklerinin Bilgisayar Destekli Analizi,"(Computer Aided Analysis of Space Harmonics in Alternating Current Machines) MSc Thesis, Turkish, ITU Science \&Technology Institute, Istanbul, 2004 
[13] Kocabaş, D.A. and Mergen, A.F., "Çok Fazll Asimetrik Sargllarda Uzay Harmoniklerinin ve Sargl Faktörünün Matlab Destekli Analizi,"(Matlab Aided Analysis of Space Harmonics and Winding Factor in Assymmetric Multi-Phase Windings) ELECO 2000, Turkish, Elektrik, Bursa, Türkiye, s.99-102, Nov 2000

[14] Kocabaş, D.A. and Mergen, A.F., "Uzay Fazörleri Ile Simetrisiz Stator Sargılarında Uzay Harmoniklerinin ve Sargl Faktörünün Bilgisayar Destekli Matrisel Analizi," (Computer Aided Matrix Analysis of Space Harmonics and Winding Factor in Assymmetric Stator Windings by Using Space Phasors) ELECO 2001, Turkish, Elektrik, Kocaeli, Türkiye, Ekim 2001

[15] Stepina J., "Non-Transformational Matrix Analysis Space Harmonics of Electrical Machines”, ELECTR. Mach. And Electromech., 4, pp.255-268, 1979

[16] Burbidge R.F., "A Rapid Method Of Analysing The Mmf Wave Of A Single Or Polyphase Winding,” Proc. IEE, 105 C, pp 307-311, 1958

[17] Stepina J., "Matrix Analysis of Space Harmonics of Asymmetrical Stator Windings,” Proc. IEE Vol. 134, Pt.B, No.4, 1987 